\title{
ANÁLISE DA REINTRODUÇÃO DO SARAMPO NO BRASIL
}

\author{
CATEGORIA: SAÚDE COLETIVA/ EPIDEMIOLOGIA
}

\section{CENTRO UNIVERSITÁRIO SÃO CAMILO}

Alvarenga, Y.D.1;

Piotto, M.R. ${ }^{1}$;

Reis, L.A.O.E.';

Oliveira, G.H.P.1;

Sequeira, M.F.';

Zenatti, C.T. ${ }^{2}$

'DISCENTES DO CENTRO UNIVERSITÁRIO SÃO CAMILO 2DOCENTE DE INFECTOLOGIA DO CENTRO UNIVERSITÁRIO SÃO CAMILO 


\title{
ANÁLISE DA REINTRODUÇÃO DO SARAMPO NO BRASIL
}

\author{
CATEGORIA: SAÚDE COLETIVA/ EPIDEMIOLOGIA
}

DESCRITORES: Sarampo, Adesão vacinal, Imunização, Epidemiologia. 


\title{
ANÁLISE DA REINTRODUÇÃO DO SARAMPO NO BRASIL
}

\author{
ALVARENGA, YD ${ }^{1}$; PIOTTO, MR ${ }^{1} ;$ REIS, LAOE ${ }^{1} ;$ OLIVEIRA, GHP ${ }^{1}$; \\ SEQUEIRA, MF ${ }^{1}$; ZENATTI, $\mathrm{CT}^{2}$
}

'DISCENTES DO CENTRO UNIVERSITÁRIO SÃO CAMILO

2DOCENTE DE INFECTOLOGIA DO CENTRO UNIVERSITÁRIO SÃO CAMILO

\section{RESUMO}

INTRODUÇÃO: O Sarampo é uma doença viral aguda, potencialmente grave, altamente contagiosa, sem tratamento específico e evitável. Ela se caracteriza por febre, tosse, coriza, conjuntivite e a presença de um exantema maculopapular de progressão crânio caudal. No cenário atual, o retorno do sarampo ameaça a saúde populacional, principalmente pela redução do número de pessoas vacinadas, levando a queda no efeito rebanho.

OBJETIVO: Elencar os principais fatores e desencadeantes para o ressurgimento do Sarampo no Brasil.

METODOLOGIA: Foi realizada uma revisão bibliográfica utilizando as bases de dados: Scielo, PubMed/Medline e Lilacs, e como descritores: "Sarampo", "Measles", "Adesão Vacinal", "vaccine", "vacina", "Imigração no Brasil", "Epidemiology" e "Epidemiologia". Foram descartadas publicações anteriores a 2015.

RESULTADOS: Os estudos demonstraram que a reincidência do Sarampo no Brasil é multicausal. Contudo, todos os textos analisados apontaram a baixa adesão vacinal como fator principal. Um motivo para essa ocorrência é a falta de informação sobre relevância da vacina (SCR) entre a população. Além deste, também foi contemplado a atual situação de imigrantes no Brasil, visto que seus países de origem normalmente não possuem política de vacinação e educação em saúde efetivas.

CONCLUSÃO: Cabe orientar o paciente a importância da vacinação, bem como realizar uma busca ativa, abrir canais de comunicação rápidos e claros explicando a necessidade de tal prevenção e os agravos que virão a ser evitados.

DESCRITORES: Sarampo, Adesão vacinal, Imunização, Epidemiologia. 


\section{ANÁLISE DA REINTRODUÇÃO DO SARAMPO NO BRASIL}

\section{INTRODUÇÃO}

O Sarampo é uma doença infecciosa viral de caráter agudo, extremamente contagiosa, potencialmente grave, sem tratamento específico e prevenível por vacinação. É um dos cinco exantemas clássicos da infância, junto com a varicela, rubéola, eritema infeccioso e roséola. Seu agente etiológico é o Vírus do sarampo, RNA-vírus, pertencente ao gênero Morbillivirus, da família Paramyxoviridae. É diagnosticado por sorologia, isolamento viral RT-PCR, swab de secreção nasofaríngea e pelo quadro clínico característico: febre alta, exantema maculopapular que pode ser acompanhado por tosse, coriza e/ou conjuntivite. Um sinal patognomônico da doença são as manchas de Koplik, que surgem na mucosa oral como pontos azul-esbranquiçados. É uma doença altamente contagiosa transmitida por gotículas e tem como profilaxia mais segura e eficaz a vacina específica contra o vírus sarampo ${ }^{11}$.

Trata-se uma doença de notificação compulsória desde 1968. Durante muitos anos foi uma doença com alta morbidade e mortalidade na infância, principalmente em lactentes. A enfermidade se comportava de maneira endêmica naquela época, com surtos anuais e descontrolados, configurando um desafio para a saúde pública. A implementação do Programa Nacional de Imunização (PNI) e de Campanhas Nacionais de vacinação reduziram de forma drástica a incidência da doença. Em 1986, foram notificados 129.942 casos de sarampo, o que representou uma incidência de 97,7 por 100.000 habitantes. Após a implantação da PNI, foi possível atingir uma cobertura vacinal satisfatória ( $95 \%$ da população vacinada), e assim, em 1992, foram notificados apenas 7.934 casos. Com os passar dos anos, o número de casos notificados foi reduzindo, até que em 2016 a OMS (Organização Mundial de saúde) considerou o sarampo erradicado no Brasil, não sendo identificado nenhum caso do vírus no período de 1 ano no país. Contudo, esta não é mais a realidade brasileira ${ }^{11}$. No início do ano de 2018 , boletins epidemiológicos demonstraram um surto da doença no Brasil, com 1735 casos confirmados até o dia 17/09/2018, recebendo destaque a Região Norte do país, principalmente, Amazonas (1358 casos confirmados) e Roraima (310 casos confirmados) ${ }^{10}$.

\section{OBJETIVO}

Desde fevereiro de 2018, o Brasil luta contra um surto de Sarampo. Diversos países da América Latina, como por exemplo a Venezuela, enfrentam o mesmo problema. Um dos motivos principais para esse quadro é a queda na cobertura vacinal e a imigração de pessoas não vacinadas para o território brasileiro. Devido ao quadro clínico grave, altamente contagioso e de morbimortalidade elevada, é essencial reconhecer e compreender os principais fatores desencadeantes para o ressurgimento desta doença. 


\section{METODOLOGIA}

Foi realizada uma revisão bibliográfica utilizando as bases de dados: Scielo, PubMed/Medline e Lilacs, e como descritores: "Measles", "Sarampo", "Vaccine", "Vacina", "Imigração no Brasil”, "Outbrack", "Surto", "Brazil”, "Brasil”, "Epidemiology" e "Epidemiologia”. Os estudos foram analisados segundo seu delineamento, metodologia empregada, resultados e conclusões.

Os critérios de exclusão utilizados foram artigos que não abordassem o retorno do sarampo no Brasil, o movimento anti-vacinal, epidemiologia do sarampo, abordagem da população a respeito da vacina do sarampo, o aumento da incidência dessa doença no território brasileiro; além de artigos que tratassem de surtos ocorridos anteriormente ao ano de 2010, e publicados antes de 2015. Os artigos selecionados foram de caráter: revisões bibliográficas, relatos de caso, estudos epidemiológicos.

Após a leitura e avaliação dos artigos, foi realizada a síntese, e análise das informações coletadas. Houve o enfoque na busca sobre o motivo do retorno do sarampo, a baixa da cobertura vacinal e a atual situação de imigrantes no Brasil e como isso impactou o retorno da doença. No total, foram analisados 10 artigos, cujos dados foram apresentados de maneira descritiva, integrando e comparando as informações e resultados encontrados.

\section{RESULTADOS E DISCUSSÃO}

Dentro do contexto e dos objetivos do presente trabalho, utilizando as bases de dados e os descritores já citados para seleção, foram encontrados 10 artigos (seis publicados em 2015; dois em 2017 e dois em 2018). Dentre eles foram analisados relatos de casos, estudos epidemiológicos e revisões, os achados levaram a elaboração de 3 pontos a serem discustidos: 1) A epidemiologia do Sarampo; 2) Cobertura vacinal no Brasil e 3) O surto e seus aspectos.

\section{1) A EPIDEMIOLOGIA DO SARAMPO}

Durante as últimas décadas o Brasil vem desempenhando um ótimo papel na luta pela erradicação do sarampo até 2020, como foi estipulado pela Organização Mundial da Saúde (OMS). Desde os anos 80, o governo brasileiro tem ampliado a cobertura vacinal da população, focando particularmente a primeira infância (crianças até 6 anos), evitando assim que a doença se instale no período de maior mortalidade e de mais fácil disseminação. Devido a este aumento vacinal através de campanhas como a de 2007 - onde foram vacinadas mais de 70 milhões de pessoas, o Brasil, de 2002 a 2014, não apresentou novos casos de sarampo (gráfico 1) ${ }^{10}$. 


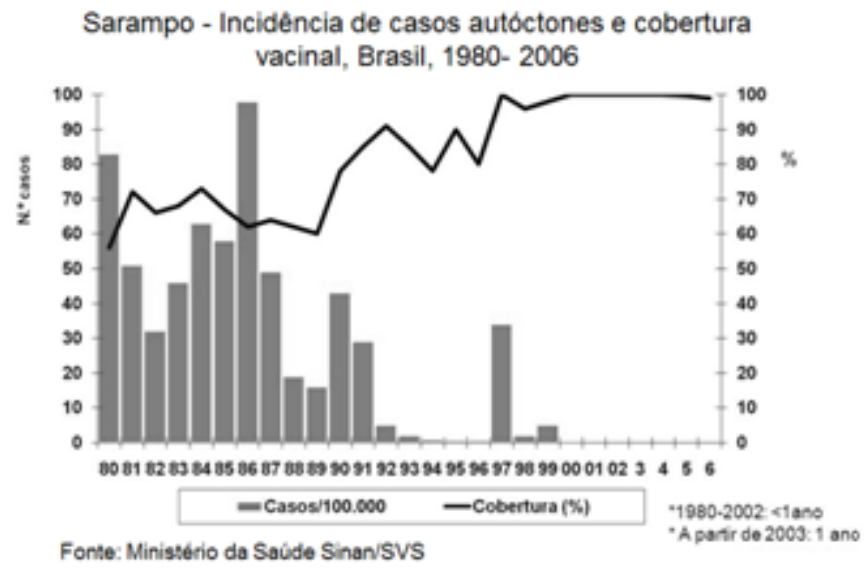

Fonte: Ministério da Saúde Sinan/SVS

Nos últimos anos a OMS tem recebido notificações de novos casos, principalmente em países europeus e africanos. O Brasil passou por um surto em 2015, onde foram notificados um total de 214 casos, 211 no Ceará, dois em São Paulo e um em Roraima (Ministério da Saúde). Em 2016, recebemos da OMS o certificado de eliminação da circulação do vírus do sarampo, declarando a América livre de tal vírus. Contudo, em julho de 2017, casos voltaram a ressurgir na Venezuela, e devido as altas taxas migratórias dessa população para o Brasil, houve um aumento no número de casos novos nos estados de fronteira ${ }^{10}$.

Quadro 1: Unidade Federativas Casos Confirmados de Sarampo - 2018

\begin{tabular}{|lc|}
\hline Unidade Federada Casos Confirmados \\
\hline Amazonas & 1358 \\
Roraima & 310 \\
Rio Grande do Sul & 24 \\
Rio de Janeiro & 18 \\
Pará & 13 \\
Sergipe & 4 \\
São Paulo & 2 \\
Rondônia & 2 \\
Brasil & 1.735 \\
Fonte: Secretaria Estadual de Saúde \\
do AM, RR, RS, RJ, PA, SE, PE, SP e \\
RO. Data: 17/09/2018;
\end{tabular}




\section{2) COBERTURA VACINAL NO BRASIL}

A imunização é uma das intervenções da saúde pública mais seguras, econômica e efetivamente, para a prevenção de doenças de agravo e óbitos. A ampliação desse cuidado foi uma das medidas responsáveis por diminuir a mortalidade infantil e a mortalidade materna, itens que fazem parte dos Objetivos de Desenvolvimento do Milênio (ODM) pela ONU em $2000^{9}$.

No Brasil, com a adoção do Plano Nacional de Imunização (PNI), a vacina se tornou gratuita, sendo dever do estado oferece-la quando esta se encontra no calendário de vacina do Ministério da Saúde e/ou da Secretária de Saúde de cada unidade federativa. Estas medidas elevaram a cobertura vacinal na população. Um inquérito vacinal, realizado nas 26 capitais brasileiras e no Distrito Federal, no período de agosto de 2007 a maio de 2008, com crianças de 18 a 30 meses de idade, mostraram os seguintes percentuais de cobertura para vacinas do Calendário Nacional de Vacinação da Criança (2006): BCG (97\%), poliomielite (96\%), DTP (difteria, tétano e coqueluche) $(94 \%)$, hepatite B $(91 \%)$ e tríplice viral (vacina sarampo, caxumba e rubéola) $(91 \%)^{9}$.

O Ministério da Saúde tem como objetivo que no mínimo 95\% da população seja vacinada, sendo assim a DTP e a tríplice viral não alcançaram este patamar na época. Contudo, esses dados se referem à média nacional, pois neste mesmo inquérito foi relatado que em 2006, 28,3\% das crianças, na faixa de 18 a 30 meses, nunca haviam sido vacinadas em São Luís -MA .

Figura 2: Sarampo

Cobertura vacinal esquema regular e reforço de vacinas em crianças de 1 ano de idade - 2011 e 2014
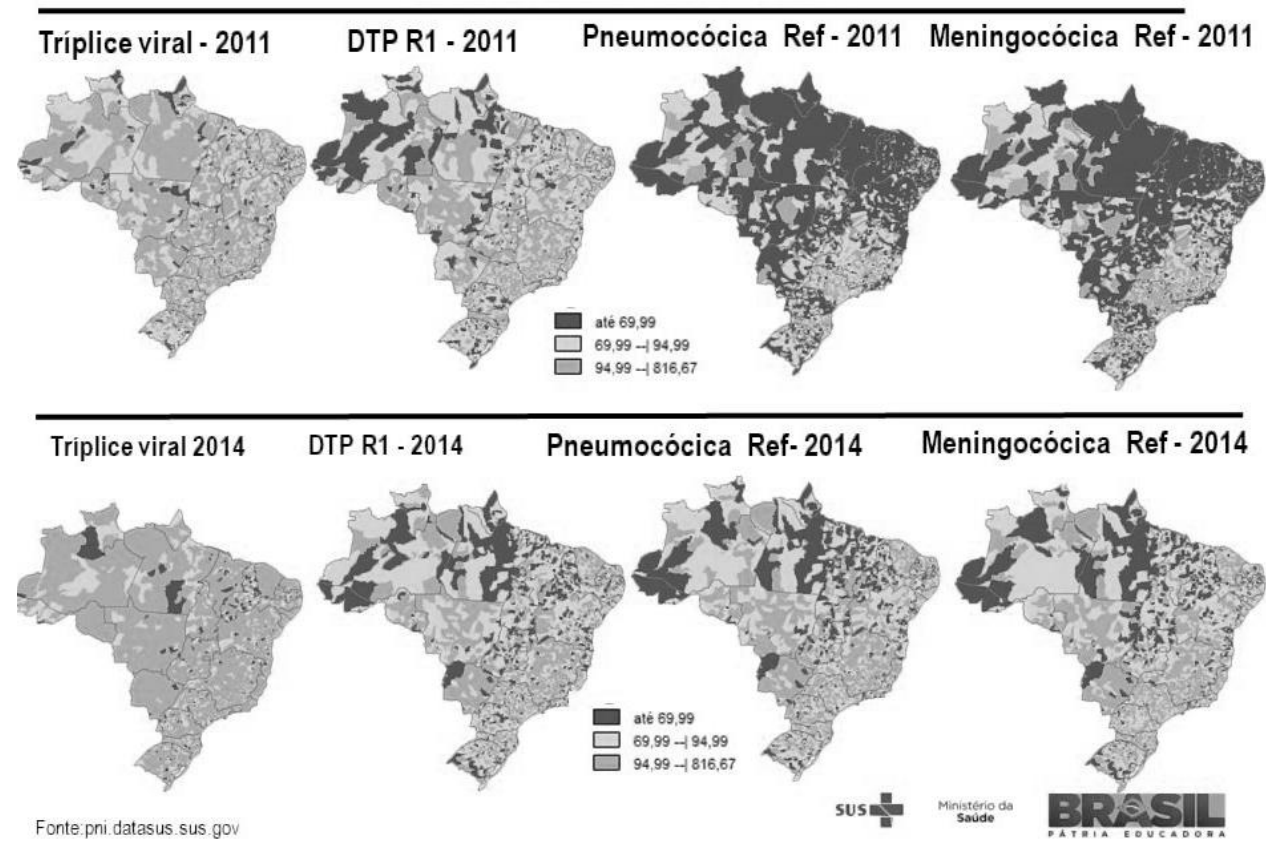

Fonte: Ministério da Saúde Sinan/SVS 
Um estudo de coorte prospectivo, realizado na cidade de São Luís -MA, entre os anos de 2010 e 2013 (SILVA et al., 2018), elucidou as características das crianças e das famílias que acabam sendo mais negligenciadas dentro da PNI. O estudo mostrou que a incompletude do calendário vacinal, que inclui a tríplice viral, foi $26 \%$ mais frequente em crianças de mães adolescentes ( $\mathrm{RP}=1,26$; IC95\%: 1,10-1,45), 1,58 vez maior quando as mães tinham menos de cinco anos de estudo ( $R P=1,58$; IC95\%: 1,21-2,06) e 52\% maior naquelas cujas mães eram tabagistas ( $R P=1,52$; IC95\%: 1,28-1,82), estes percentuais foram aumentados quando o número de irmãos era maior ou a gravidez não era programada 9 .

\section{3) O SURTO E SEUS ASPECTOS}

Tem-se observado a reincidência do sarampo no Brasil desde o final de 2013, que vem mantendo-se persistente mesmo depois de várias medidas emergenciais dos estados e prefeituras para diminuir o aumento de casos. Iniciou-se no estado do Pernambuco, onde foram notificados 224 casos, sendo em sua maioria cepas do genótipo D8, mesmo precursor do surto no continente europeu no início de 2013. Este surto se espalhou pelos estados fronteiriços, sendo no Ceará 694 casos em 2014. Este foi o primeiro surto nos anos 2000, o que levou a uma investigação epidemiológica para identificar suas razões. Os estudos revelaram uma forte probabilidade da origem externa da doença, devido ao alto número de estrangeiros que chegaram ao Brasil. $O$ alto número de casos também pode ser atribuído a cobertura vacinal desses estados que mesmo contando com números gerais maior que 95\%, possui áreas onde esta porcentagem não passa de 56\% (LEITE; BEREZIN, 2015) ${ }^{6}$.

Figura 3 Sarampo

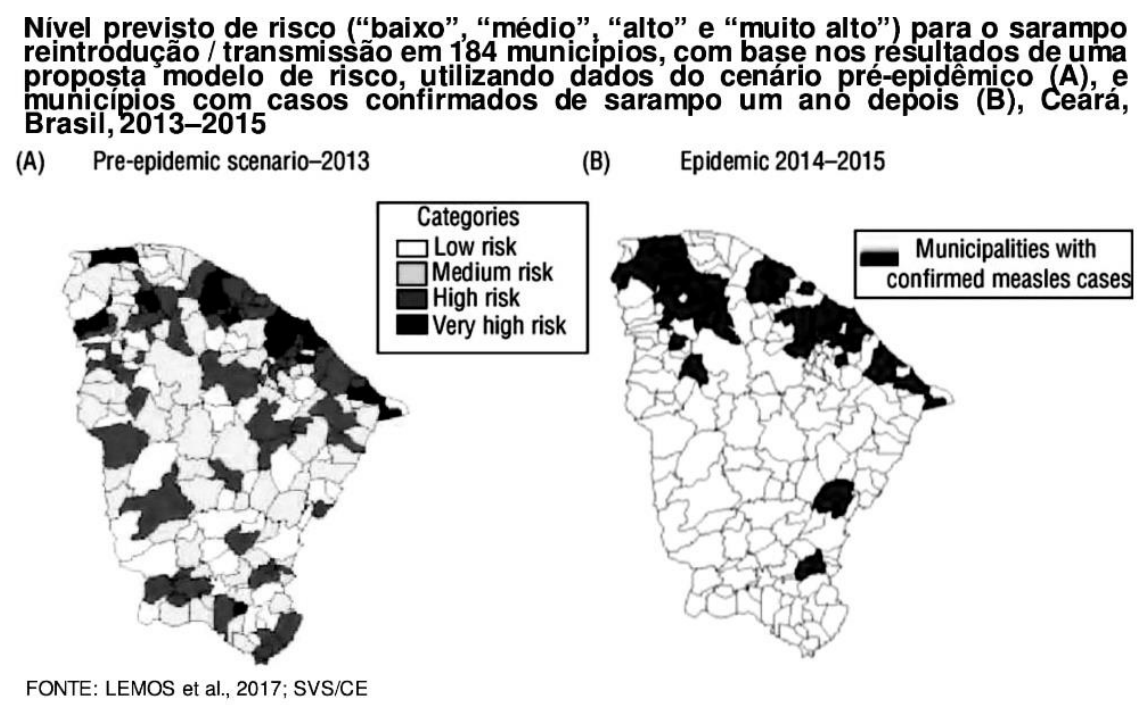

Fonte: LEMOS ET AL,2017, SVS/CE

No final de 2017 e início de 2018, outro surto de sarampo foi identificado no Brasil, também com culpa referida ao estrangeiro. A onda migratória Venezuela-Brasil, devido aos problemas 
econômicos enfrentado pelo país bolivariano, as cidades e os estados brasileiros em suas fronteiras tem recebido milhares de venezuelanos que devido à falta de um PNI forte, não estão imunizados, e acabam causando a recirculação do vírus na região e auxiliando na disseminação sobre os não vacinados ${ }^{10}$.

Uma averiguação feita pelo Ministério da Saúde em 2018 na região Norte do país, revelou um aumento exponencial nos últimos meses. O último caso de sarampo no estado do Amazonas havia ocorrido no final do ano 2000 , contudo de janeiro a setembro de 2018 , o acumulado de novos casos chegou a 1358, somando 1735 casos em todo Brasil. Assim como no surto de 2013, aspectos da não vacinação nas comunidades mais afastadas também favorecem 0 reaparecimento nesses níveis do patógeno ${ }^{10}$.

Estudos também trazem as ações e os movimentos antivacina como coautores do aumento desses surtos. Diferentemente dos países mais ricos, onde estes movimentos são alimentados por ideias conspiratórias de governo, ou por puro idealismo, no Brasil isso ocorre majoritariamente por desinformação da população, principalmente entre as classes D e E. O que fez o governo, atualmente, estender as campanhas de vacinação para um período maior de tempo, abordando todas as vacinas do calendário vacinal ${ }^{10}$.

\section{CONCLUSÃO}

A incidência de novos casos de Sarampo está associada principalmente com a baixa cobertura vacinal e a imigração de pessoas não vacinadas para a Região Norte do país. A baixa adesão vacinal é decorrente do movimento antivacina e da falta de informação sobre a importância da vacinação no contexto individual e coletivo. Para reverter esse quadro, deve ser promovida conscientização populacional acerca desse método de prevenção primária.

Os profissionais da saúde, sendo os responsáveis por transmitir as orientações, devem estar preparados, com base em informações científicas, para conscientizar os usuários alvo da Campanha da Vacina Tríplice Viral SCR (Sarampo Caxumba Rubéola). Deve-se abordar, através de canais de comunicação rápidos e claros, a necessidade da vacinação, os agravos que serão evitados e a importância no efeito rebanho. Além disso, a busca ativa de nativos e imigrantes não vacinados tem alta relevância e não deve ser negligenciada.

\section{REFERÊNCIAS}

1) JESUS, Hiane Santos de et al. Investigação de surto de sarampo no Estado do Pará na era da eliminação da doença no Brasil. Cadernos de Saúde Pública, [s.I.], v. 31, n. 10, p.2241-2246, out. 2015. FapUNIFESP (SciELO). http://dx.doi.org/10.1590/0102$311 \times 00017515$. 
2) GOODSON, James L.; SEWARD, Jane F.. Measles 50 Years After Use of Measles Vaccine. Infectious Disease Clinics Of North America, [s.I.], v. 29, n. 4, p.725-743, dez. 2015. Elsevier BV. http://dx.doi.org/10.1016/j.idc.2015.08.001.

3) BORBA, Rodrigo C.n.; VIDAL, Vinícius M.; MOREIRA, Lilian O.. The re-emergency and persistence of vaccine preventable diseases. Anais da Academia Brasileira de Ciências, [s.I.], v. 87, n. 2, p.1311-1322, 25 ago. 2015. FapUNIFESP (SciELO). http://dx.doi.org/10.1590/0001-3765201520140663.

4) MOKDAD, Ali H. et al. Missed Opportunities for Measles, Mumps, and Rubella (MMR) Immunization in Mesoamerica: Potential Impact on Coverage and Days at Risk. Plos One, [s.I.], v. 10, n. 10, p.1-18, 27 out. 2015. Public Library of Science (PLoS). http://dx.doi.org/10.1371/journal.pone.0139680.

5) LEMOS, Daniele et al. Risk analysis for the reintroduction and transmission of measles in the post-elimination period in the Americas. Revista Panamericana de Salud Pública, [s.l.], p.1-7, 2017. Pan American Health Organization. http://dx.doi.org/10.26633/rpsp.2017.157.

6) LEITE, Robério Dias; BEREZIN, Eitan Naaman. Measles in Latin America: Current Situation. Journal Of The Pediatric Infectious Diseases Society, [s.I.], v. 4, n. 3, p.179-181, 6 ago. 2015. Oxford University Press (OUP). http://dx.doi.org/10.1093/jpids/piv047.

7) ROCHA, Hermano A.I. et al. Factors associated with non-vaccination against measles in northeastern Brazil: Clues about causes of the 2015 outbreak. Vaccine, [s.l.], v. 33, n. 38, p.4969-4974, set. 2015. Elsevier BV. http://dx.doi.org/10.1016/j.vaccine.2015.07.027.

8) LEMOS, Daniele Rocha Queiroz et al. Measles epidemic in Brazil in the postelimination period: Coordinated response and containment strategies. Vaccine, [s.I.], v. 35, n. 13, p.1721-1728, mar. 2017. Elsevier BV. http://dx.doi.org/10.1016/j.vaccine.2017.02.023.

9) SILVA, Francelena de Sousa et al. Incompletude vacinal infantil de vacinas novas e antigas e fatores associados: coorte de nascimento BRISA, São Luís, Maranhão, Nordeste do Brasil. Cadernos de Saúde Pública, [s.I.], v. 34, n. 3, p.1-21, 12 mar. 2018. FapUNIFESP (SciELO). http://dx.doi.org/10.1590/0102-311x00041717.

10) BRASIL. MINISTÉRIO DA SAÚDE. Situação do Sarampo no Brasil 2018. Disponível em: http://portalarquivos2.saude.gov.br/images/pdf/2018/setembro/19/informe-sarampo23.pdf. Acesso em: 17 set. 2018.

11) DOMINGUES, Carla Magda Allan S. et al . A evolução do sarampo no Brasil e a situação atual. Inf. Epidemiol. Sus, Brasília , v. 6, n. 1, p. 7-19, mar. 1997. Disponível em <http://scielo.iec.gov.br/scielo.php?script=sci_arttext\&pid=S010416731997000100002\&lng=pt\&nrm=iso>. acessos em 23 set. 2018. http://dx.doi.org/10.5123/S0104-16731997000100002. 